\title{
A Multi-level Analysis of the Impact of Shared Leadership in Diverse Virtual Teams
}

\author{
Lionel P. Robert Jr. \\ School of Information \\ University of Michigan \\ 4417 North Quad, 105 South State St., Ann Arbor, MI 48109 \\ lprobert@umich.edu
}

\begin{abstract}
Although, organizations are using more virtual teams to accomplish work, they are finding it difficult to use traditional forms of leadership to manage these teams. Many organizations are encouraging a shared leadership approach over the traditional individual leader. Yet, there have been only a few empirical studies directly examining the effectiveness of such an approach and none have taken into account the team diversity. To address this gap, this paper reports the results of an empirical examination of the impacts of shared leadership in virtual teams. Results confirm the proposed research model. The impacts of shared leadership are multilevel and vary by race and gender. In addition, while shared leadership promotes team satisfaction despite prior assumptions, it actually reduces rather than increases team performance.
\end{abstract}

\section{Author Keywords}

Share leadership; virtual team; team identification; multi-level analysis.

\section{ACM Classification Keywords}

\section{H.3.5; H.4.3; K.6.0}

\section{INTRODUCTION}

It is broadly recognized that teams have better informational resources than individuals, making them ideal for accomplishing knowledge-intensive work [45]. Unlike face to face teams, virtual teams allow organizations to assemble members to solve problems without the traditional requirements associated with collocation (e.g. same time and space) $[16,39,46]$. This paper defines virtual teams as teams with members who are geographically dispersed and rely primarily on some type of technology mediated communication $[3,45,46]$. The ability to manage distributed teams has become more important as organizations and their work becomes dispersed [3, 16, 46].

Prior research on leadership has typically defined it as an individual trait or individual role $[12,13]$. These studies

Permission to make digital or hard copies of all or part of this work for personal or classroom use is granted without fee provided that copies are not made or distributed for profit or commercial advantage and that copies bear this notice and the full citation on the first page. To copy otherwise, or republish, to post on servers or to redistribute to lists, requires prior specific permission and/or a fee.

CSCW'13, February 23-27, 2013, San Antonio, Texas, USA.

Copyright 2013 ACM 978-1-4503-1331-5/13/02 ...\$15.00. have typically focused on how one individual influences the behavior of other team members to help meet team objectives [57]. However, many problems addressed by virtual teams are often complex and require specialized knowledge to solve that no single individual possesses [45]. In these situations it is difficult to have one person in charge of the overall team. This problem is only exacerbated when these teams work at a distance [2, 3, 35]. As a result, there has been a shift away from traditional hierarchical leadership structures to a more decentralized or shared leadership [13, 40].

Virtual teams are more likely than face to face teams to be demographically diverse [30]. Race and gender diversity, like many types of diversity, have been viewed as a double edged sword [55]. Race and gender diversity provide informational benefits for decision making and creative problem-solving, yet they also pose barriers to team unity [36]. Prior research would indicate that feelings of exclusion and inequality often leave racial and gender minorities feeling socially isolated which hinders the development of team identification [33]. As a result, gender and racially diverse teams are often confronted with the challenge of determining how to mitigate the barriers to establish a unified team identity [36, 37]. This is particularly pertinent given that virtual teams are more likely to have difficulty developing internal bonds and often report lower levels of satisfaction [30].

Shared leadership is the distribution of leadership among team members and is characterized by the sharing of leadership roles [12, 13]. Shared leadership, however, offers the possibility for every team member to be included in team decisions which potentially promises more inclusion and better team experiences. This paper seeks to build on prior literature examining shared leadership in virtual teams [5, 13]. The research question this study attempts to address is: "How does shared leadership impact the identification, satisfaction and actual performance of virtual teams?" This study has three goals: 1) To examine the impacts of shared leadership on an individual's willingness to identify with their team in light of their race and gender. Team identification has been found to be an important process variable for the success of virtual teams $[9,45]$. However, little research has been done to understand the conditions that facilitate team identification 
when these teams are racially and gender diverse. 2) Investigate the impact of shared leadership on team satisfaction. Virtual teams are often criticized for being overly sterile and too task focused [44]. As work becomes both more virtual and collaborative, understanding what factors facilitate a positive team work environment becomes increasingly important 3) Examine the impact of shared leadership on the performance of virtual teams. Prior research has only posited positive impacts between shared leadership and virtual team performance $[5,13]$; however, there are reasons to believe that shared leadership could potentially decrease the performance of virtual teams.

To address these gaps in the virtual team literature this paper proposes a multi-level research model that explains the relationship between shared leadership, identification, satisfaction and team performance. A study was conducted involving 78 individuals in 22 virtual teams to empirically test the proposed model. Results generally support the research model. Overall, this paper contributes to the CSCW literature by demonstrating the important role of shared leadership in computer supported environments.

\section{RELATED WORK}

Traditional views of leadership describe it as a process whereby an individual influences the attitudes and behaviors of other individuals [12, 13, 54]. In traditional face to face settings leaders oversee the work of other team members and set standards and expectations about how the team is expected to behave [54]. The literature on face to face teams can be divided into task versus relationship based leadership or formal static versus informal emergent leadership [6, 32 56]. Task leadership behaviors are behaviors directed at performing task while relationship behaviors are focused on promoting and maintaining cohesion, motivation and communication [32, 56]. This literature tends to examine how proficient individual leaders are at directing teams during task performance and/or promoting social support [6]. Formal static leadership occur when an individual is formally recognized as the team leader before the team begins work while an informal emergent leader is someone who is not formally recognized as the team leader but emerges as the leader through a series of interactions with other team members [59]. Research examining the former focuses more on how individuals exercise influence through formal organizational mechanisms while the latter examines how emergent leaders facilitate influence over informal mechanisms.

\section{Leadership in Virtual Teams}

Although virtuality can be measured in many different ways two dimensions remain constant across all definitions: geographic dispersion and reliance on electronic communication [22, 19, 24, 46, 38]. Other definitions of virtuality have included cultural differences, time zone differences, the number of remote workers and the number of members located at each work site [22, 38]. This study examines virtuality as geographic dispersion and the inability to rely on face to face interactions as the primary mode of communication [46].

Virtual team leadership can be defined as influence mediated through information and communication technologies [4]. Geographic dispersion makes it difficult for leaders to directly oversee the work of others [21]. This lack of direct supervision and the need to influence others through information and communication technology mediation is what differentiates leadership in virtual teams from face to face teams [54]. Despite the difficulties embedded in leading virtual teams prior research has shown that leadership matters for online collaborations [27, 58]. For example, [42] found that leadership was directly and positively associated with the performance of virtual teams. Yet, leadership still remains a much understudied topic in virtual team literature [54].

\section{Shared Leadership}

Leadership can also be viewed as distributed or focused [12]. The traditional view of leadership is an example of focused leadership where one individual is the single focus point. Distributed leadership recognizes that leadership can reside in more than one individual [20]. Distributed leadership is based on the idea that leadership is a series of functions that any member can perform at any time rather than a role than one member fulfills [40]. In this view any member can be a leader at any time and members often rotate leadership positions [12].

Shared leadership is an informal emergent distributed view of leadership. It has been conceptualized as a "dynamic, unfolding, interactive influence process among individuals, where the objective is to lead one another toward the achievement of collective goals." [41]. Shared leadership can manifest through the rotation of leadership positions where one member steps forward to take charge then steps back to allow someone else to take charge [40]. Shared leadership can also take the form of a constant distribution of responsibility where each member maintains a leadership position in a particular area at all times. Prior literature has not viewed shared leadership as an example of a leaderless team but instead as a team with many leaders [41]. Selfmanaged teams are one example of teams that use shared leadership [13].

Shared leadership often emerges because individuals possess unique expertise [41]. In these situations no single team leader could possess the needed expertise to effectively lead a team [40]. As a result, leadership is often based on who has the expertise to address a given, specific task at the time. However, shared leadership might also emerge out of time availability. Team members might engage in taking turns based on who has the time to oversee a particular part of the team's task. 
There are relatively few empirical studies that have directly examined the impact of shared leadership in virtual teams. These studies have found that shared leadership increases team cohesion and positive communication behaviors like cooperation, exchange of information, respect for others, and trust $[5,13,26]$. However, neither [5] nor [13] found a direct link between shared leadership and team performance. Carte et al. [13] did find that high performing virtual teams displayed higher levels of shared leadership than low performing virtual teams. Unfortunately, there was no statistical connection between shared leadership and team performance [25]. Lee et al. [26] did however find a positive link between shared leadership and the selfreported creativity of virtual teams. A related study by Zhu et al. [58] found that shared leadership influenced individual contributions to Wikipedia.

Team Identification in Virtual Teams

Team identification is defined as the extent to which members are psychologically identified their team [47]. When members identify with their team they will see their team's success as their success [1]. As such, when members have strong identification with their team they are more likely to engage in productive behaviors that support the team [34]. Members who are strongly identified with the team are also less likely to engage in unproductive behaviors like effort-withholding [48]. Team identification is important to the success of both face to face and virtual teams $[34,22,45]$.

Although past studies in face to face teams found that race and gender can have negative impacts on team identification [52] can we expect the same problems to exist in virtual teams that are geographically separated? Fiol and O'Connor [17] thought so. They directly proposed that team diversity could reduce the salience of the team as a target for identification in both face to face and virtual teams. Recent research has indicated that differences in geographic location can act as triggers of social categorization in virtual teams [43, 38]. However, [43] found that the effects of geographic location were significantly stronger when collocated subgroups were more homogeneous in attributes like nationality. This provides evidence that demographic variables like gender and race may have an impact on constructs like identification in virtual teams over and above geographic subgroups. In addition, Cramton [15]) has shown that in teams where members are totally geographically dispersed and there are no geographic subgroups; members were still inclined to level harsher judgments against each other because they lack contextual information about dispersed others. Taken together we can expect attributes like race and gender to influence team identification in virtual teams.

\section{RESEARCH MODEL}

This paper puts forth a multilevel research model of shared leadership in virtual teams. At the individual level the paper posits that the influence of shared leadership on an individual's identification with their virtual team is moderated by that individual's gender and race. This model also proposes that shared leadership, at the team level, increases team satisfaction and decreases team performance while team identification increases both team satisfaction and team performance. Figure 1 provides a summary of these arguments, which are elaborated below

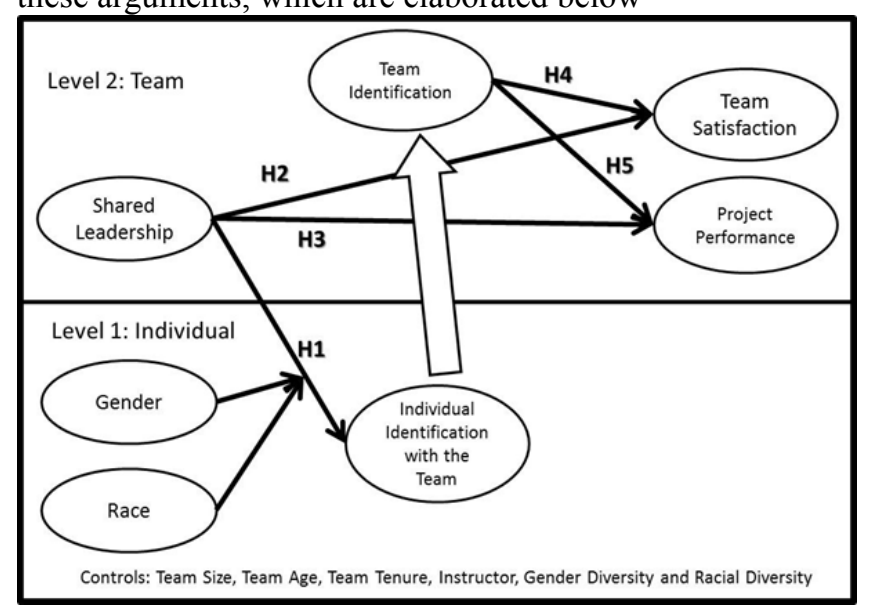

Figure 1: Research Model

Shared leadership can be described as a collective team process where individual team members share the roles and responsibilities of a traditional leader [40]. Shared leadership operates through a series of interactions and negotiations between team members that lead to the sharing of leadership responsibilities [12]. In teams with a high degree of shared leadership we would expect every member to contribute to decision making. These teams should be more inclined to consider the opinions and ideas of everyone [40]. Members of virtual teams with high levels of shared leadership will have stronger feelings of equality and greater levels of participation. Higher levels of equality and participation have been shown to be associated with increases in an individual's identification with their team [45]. As such, we would expect that shared leadership would increase an individual's identification with their virtual team.

However, we would expect this impact to be moderated by gender and race. Shared leadership necessitates the sharing of power and influence among all team members [40]. Prior research has found that feelings of inequality and a lack of influence are stronger for women and racial minorities than white males [33]. As such, we would expect that the impact of shared leadership on an individual's identification with their virtual team should be stronger and more positive for women and racial minorities than for white males. In addition, we would expect the impact of shared leadership to be stronger for racial minorities than for white females and for racial minority females than racial minority males.

H1) The effects of shared leadership on individual identification with their virtual team should vary by both race and gender. 
Shared leadership results in a pattern of reciprocal exchanges among team members [12]. These patterns of interactions promote inter-team relations [41]. Virtual teams with high levels of shared leadership require all team members to engage in roles and responsibility equally. This should reduce social loafing in teams which decreases team morale [3, 49]. This, in part, explains why shared leadership has been found to promote more cohesive bonds [5]. These teams have been found to care more about each other and pull together as a team when things get tough [13]. It is likely that the strong cohesive bonds and high levels of social support should translate into a more enjoyable team experience. As such, we would expect shared leadership to increase the degree of team satisfaction.

H2) Shared leadership should increase team satisfaction in virtual teams.

Although most studies assume that the link between shared leadership and team performance is positive many empirical studies have found little or no association [13]. In fact, most of the studies that have found a strong positive relationship between shared leadership and team performance have used perceptual measures by team members as surrogates of team performance [12]. For example, Lee et al. [26] found a positive link between shared leadership and team creativity, but creativity was a self-reported outcome. There seems to be very little evidence that suggests that shared leadership increases a team level objective performance variable. Although there are many reasons to believe that shared leadership may increase team performance there are also many reasons to believe that shared leadership could reduce team performance.

Popular literature has long devalued the idea of leadership by committee [28]. When more than one person is in charge often no one is in charge. Sharing leadership functions across an entire team could lead to coordination problems like determining who is doing what and when. This, in turn, could lead to a lack of overall direction and the inefficient allocation of resources. Virtual teams with high levels of shared leadership may focus too much on trying to accommodate everyone. This could lead to virtual teams putting the maintenance of good social relations ahead of actual team performance. As such, there is some theory to suggest that shared leadership may decrease team performance.

\section{H3) Shared Leadership should decrease the performance of virtual teams.}

Team identification has been viewed as an important team process variable $[9,22,45$, and 53]. Team identification is an emotional attachment that team members have with their team $[23,50]$. Identification with a team is said to occur when an individual believes that their team represents their values and beliefs [23, 50]. When members identify with their virtual team, their individual goals and personal interests recede and the goals and interest of their team dominate their actions [45]. Not surprisingly, team identification is positively associated with reduction in team conflict [16] and positively associated with satisfaction [29] and team performance [45] in face to face teams. As such, theory would suggest that team identification should be positively related to both team satisfaction and team performance in virtual teams.

H4) Team identification should positively influence team satisfaction in virtual teams.

H5) Team identification should positively influence team performance in virtual teams.

\section{METHOD}

\section{Participants}

The participants were students enrolled at a large public university. The graduate students' ages ranged from 23 to 68 with a mean of 37.83 . Thirty-two percent of the students were females and 28 percent were non-white. All the participants were US citizens. A total of 78 students in 22 teams participated in the study. Team size ranged from 3 to 5. Team projects lasted from 15 to 100 days. Although the team project was a class requirement as part of their course the students received extra credit for completing the survey.

\section{Data Collection}

Data was collected from an online global campus designed to provide distance education to working professionals. Typically, individuals were randomly assigned to teams. However, the final decision was ultimately determined by each instructor. In fact, all decisions about team size, projects, scoring and so forth, were made by each instructor with no input from the paper's author(s). Instructors were not aware of the research question or hypotheses being tested and none of the classes were taught by the author(s).

\section{Measurement}

The survey was web-based. We assured team members that their responses were confidential and would not be seen by their instructors. The survey employed established multiitem scales, which we summarized below. A seven-point Likert scale was used to measure both team identification and satisfaction.

\section{Control Variables}

We used several control variables to reduce the possibility of alternative explanations. These included team age, team size and team tenure (life of the team), gender and racial diversity of the team and instructor. There were two sets of instructors/classes so a dummy variable of 0 or 1 was used. Gender and racial diversity were calculated via Blau's [7] index. Blau's index is defined as: $\mathrm{H}=1-\mathrm{p}_{\mathrm{i}}^{2}$. Where $\mathrm{H}$ is the heterogeneity score of a group, $\mathrm{p}$ is the proportion of team members who fall into a particular in a category, and $i$ is the number of different categories represented in the team. 


\section{Independent Variables}

Individual gender and race were obtained by asking the individual to provide a response to questions on the online survey. Race was coded as white or non-white, 0 or 1 respectively. Gender was coded as female or male, 0 or 1 respectively.

\begin{tabular}{|l|c|c|c|c|}
\hline & Female & Male & White & Black \\
\hline Team 1 & 3 & 1 & 1 & 2 \\
\hline Team 2 & 2 & 1 & 2 & 1 \\
\hline Team 3 & 2 & 1 & 2 & 1 \\
\hline Team 4 & 3 & 1 & 3 & 1 \\
\hline Team 5 & 2 & 2 & 1 & 3 \\
\hline Team 6 & 3 & 2 & 2 & 3 \\
\hline Team 7 & 3 & 1 & 4 & 0 \\
\hline Team 8 & 2 & 1 & 2 & 1 \\
\hline Team 9 & 5 & 0 & 5 & 0 \\
\hline Team 10 & 4 & 1 & 4 & 1 \\
\hline Team 11 & 3 & 0 & 2 & 1 \\
\hline Team 12 & 1 & 2 & 3 & 0 \\
\hline Team 13 & 3 & 0 & 1 & 2 \\
\hline Team 14 & 2 & 1 & 3 & 0 \\
\hline Team 15 & 3 & 0 & 3 & 0 \\
\hline Team 16 & 3 & 1 & 3 & 1 \\
\hline Team 17 & 2 & 2 & 4 & 0 \\
\hline Team 18 & 0 & 3 & 3 & 0 \\
\hline Team 19 & 1 & 3 & 2 & 2 \\
\hline Team 20 & 4 & 0 & 1 & 3 \\
\hline Team 21 & 2 & 1 & 3 & 0 \\
\hline Team 22 & 3 & 0 & 3 & 0 \\
\hline
\end{tabular}

Table 1: Team Demographics

Shared leadership was measured via a social network approach based on density [12,31]. Density was calculated by measuring the total amount of leadership displayed by team members as perceived by their teammates. Density was defined as: $\mathrm{S} / 7 \mathrm{~N}(\mathrm{~N}-1)$. In this equation, $\mathrm{S}$ is the sum of all values that each team members would rate each other for leadership. $\mathrm{N}$ is the number of team members; $\mathrm{N}(\mathrm{N}-1)$ is the total number of possible ties in a team. Each team member rated each of his/her teammate (1, "not at all," to 7 , "to a very great extent") on the following question: "To what degree does your team rely on this individual for leadership?" Shared leadership is a team level construct, measured as the density of leadership displayed by all team members. The values ranged from 0 to 1 with the lower number indicating that only a few members displayed leadership and the high number indicating that most or all members displayed leadership.

\section{Dependent Variables}

Identification with the team was a 4 item scale, based on Brown et al. [11]. Items included, "I consider the team's success my success" and "The team is important to me as a person." Team satisfaction was measured using a two item scale that was a modified version of Briggs et al. [10]. Briggs et al. [10] focused on meeting satisfaction so the items were altered to better reflect the context of the current study. The two items were "I was satisfied with how we completed the team project" and "Looking back I was pleased with how we completed the team project."

Team performance was measured by the score the team received on their team project. The team project was an organizational needs analysis. The organizational needs analysis project included an assessment of what capabilities the organization had and what was needed in the future. The team submitted one project to their instructor. Instructors employed a slightly different grading system for the team projects. To reduce the differences among the classes a standardized score was used. The standardized score was the ratio of the number of points the team earned on the project over the maximum possible number of points that the team could have. This project performance scores ranged from 0 to 100 . There were two instructors. 13 teams were graded by one instructor and 9 by the other.

\section{RESULTS}

The virtual teams in this study were composed of American graduate student teams all taking classes from different locations normally at their home. Because all subjects took courses online it was assumed that all virtual teams were fully dispersed. These teams relied heavily on the use of electronic communication. Teams were asked about their technology use. Scales range from 0 to 6,0 indicating no use and 6 indicating extremely frequent use of electronic technology. The mean use and standard deviation of use per technology was: email 4.6 (.92), synchronous chat 2.3 (1.16), phone $2.2(2.2)$ and video .10 (.4). Results indicate that most teams relied on email as the primary form of communication.

Psychometric properties were analyzed for each construct. The Cronbach alpha for team identification and team satisfaction was .78 and .97 respectively, both indicating adequate reliability [18]. Next, the intra-class correlation coefficients (ICC) were calculated for both latent constructs. The ICC is used to both justify using a multilevel analysis by providing evidence that team membership should be accounted for in the analysis and for demonstrating that the average can be used as a team level construct [46]. ICC values of above .10 have been used to provide evidence that there is a significant team effect [8]. The ICC for team identification was .25 indicating a significant team effect and providing justification for 
employing a multi-level analysis approach to account for team membership and the use of team identity as team level construct [8]. The ICC for team satisfaction was .40 providing justification for aggregating satisfaction to the team level of analysis [8].

Convergent and discriminant validity were accessed two ways. First a factor loading was done which is seen in Table 2. All items loaded at the .7 or above level on each of their constructs while no cross loadings were above .35 . Both are clear indications of convergent and discriminant validity [18]. Second, the square root of the average variance extracted (AVE) values for each latent construct, which represent internal convergent validity, were compared with the correlations of other latent constructs. The AVEs for team identification and team satisfaction were .95 and .98 . Well above the recommended .50 thus providing further evidence of convergent validity [18]. The correlation between team identification and team satisfaction was .3, found in Table 3, which was well below their respective square roots of their AVE, thus indicating discriminant validity. Table 3 presents the descriptive statistics including mean, standard deviation and the correlations for the constructs in the model.

Hypothesis 1, posited that the effect of shared leadership at the team level will be dependent on an individual race and gender. This required the use of multi-level analysis [49, 56]. To account for the nested nature of the data, SPSS 20.0 mixed model package was used to perform hierarchical linear modeling (HLM) to test the proposed model. The remaining hypotheses: $2,3,4,5$ were tested using OLS regression at the team level. The results of the multi-level analysis are shown in Table 3. Model 1 shows the effects of control variables on the dependent variables. Model 2 shows the direct effects of the individual level variables. Model 3 shows the direct effects of the team level variables. Model 4 shows the impact of the two-way cross level interactions effects. Model 5 includes the three-way cross level interaction effect. We saw that there was a significant increase in the amount of variance explained between the final model and all other models.

\begin{tabular}{|l|c|c|}
\hline & $\begin{array}{c}\text { Team } \\
\text { Satisfaction }\end{array}$ & $\begin{array}{c}\text { Team } \\
\text { Identification }\end{array}$ \\
\hline Team Sat. 1 & $\mathbf{. 9 8}$ & .12 \\
\hline Team Sat. 2 & .97 & .13 \\
\hline Team Ident. 1 & .13 & $\mathbf{. 8 5}$ \\
\hline Team Ident. 2 & .34 & $\mathbf{. 8 3}$ \\
\hline Team Ident. 3 & .19 & $\mathbf{. 7 0}$ \\
\hline
\end{tabular}

Table 2: Factor Loadings

Hypothesis 1, the effects of shared leadership on individual identification should vary by both race and gender, was supported. Model 1 included only the control variables. The control variables: size, tenure, team age and instructor were all non-significant in every model (see Table 3). Model 2 included the level one or individual main effect variables: gender and race. Model 3 included the level two or team level main effects. Model 4 included the two-way cross level interactions. The final model explained $17 \%$ of an individual's identification with the team $(p<.001)$. The twoway cross level interactions between gender and race $(\beta=-$ $7.16, \mathrm{p}<.05)$ were significant. The three-way cross level interactions between shared leadership, race and gender were also significant $(\beta=10.5, \mathrm{p}<.05)$. The three-way cross level interaction is plotted in Figure 2.

Figure 2, displays four lines. Line 1 displays the slope for non-white males. Line 1 shows that as shared leadership increases within a team (or in other words as equality increases) minority males identified more with the team. Line 2 represents white males. The amount of shared leadership has relatively little or no impact on the level of identification with the team for white males. Line 3 represents minority females. Increases in shared leadership reduced the level of identification with the team. Line 4 represents white females. Line 4 clearly displays a strong positive relationship with shared leadership and identification with the team. Overall, the impact of shared leadership varied by race and gender but not necessarily in the way predicted.

Hypothesis 2-5 was tested by using OLS. The results are shown in Table 4. Model 1 shows the effects of the control variables on the dependent variables. Model 2 includes the direct effects of shared leadership and team identity and in both cases the inclusion of the direct effects significantly increased the variance explained.

Hypothesis 2, shared leadership should increase team satisfaction, was supported $(\beta=5.01 ; p<.01)$. Hypothesis 3 , shared Leadership should decrease team performance, was also supported $(\beta=-28.7 ; p<.05)$. Shared leadership increased team satisfaction but decreased team performance. Hypothesis 4, team identification should positively influence team satisfaction, was not supported $(\beta=.71 ; p>.05)$. Hypothesis 5 , team identification should positively influence team performance, was supported $(\beta=$ $6.21 ; \mathrm{p}<.05)$. Team identification has no effect on team satisfaction but increases team performance. The final model for team satisfaction and team performance explained $64 \%$ and $62 \%$ percent of the variance respectively. The effect sizes for team satisfaction and team performance are 1.77 and 1.63 respectively. Both are defined by Cohen [14] as large effect sizes. 


\begin{tabular}{|l|l|c|c|c|c|c|c|c|c|c|}
\hline & Variable & Mean & $\begin{array}{c}\text { Std. } \\
\text { Dev. }\end{array}$ & 1 & 2 & 3 & 4 & 5 & 6 & 7 \\
\hline 1 & Team Age & 37.7 & 6.4 & & & & & & & \\
\hline 2 & Team Size & 3.6 & 0.73 & 0.1 & & & & & & \\
\hline 3 & Tenure & 48.7 & 30.8 & -0.16 & 0.22 & & & & & \\
\hline 4 & Shared Lead & 0.71 & 0.12 & 0.28 & -0.14 & -0.09 & & & & \\
\hline 5 & Gender Div. & 0.27 & 0.21 & -0.22 & 0.18 & 0.2 & -0.07 & & & \\
\hline 6 & Racial Div. & 0.27 & 0.29 & -0.13 & 0.15 & -0.04 & -0.08 & 0 & & \\
\hline 7 & Identification & 5.56 & 0.54 & 0.13 & -0.16 & 0.08 & 0.2 & -0.1 & -0.1 & \\
\hline 8 & Satisfaction & 5.78 & 1 & 0.13 & 0.05 & 0.08 & $.65^{* *}$ & -0.2 & -0.3 & 0 \\
\hline
\end{tabular}

${ }^{*} \mathrm{p}<.05 ;{ }^{* *} \mathrm{p}<.01, \mathrm{n}=22$

Table 3: Correlations Matrix

\begin{tabular}{|c|c|c|c|c|c|}
\hline $\begin{array}{c}\text { Independent } \\
\text { Variables }\end{array}$ & Model 1 & Model 2 & Model 3 & Model 4 & Model 5 \\
\hline Team Size & -0.12 & -0.15 & -0.19 & -0.18 & -0.12 \\
\hline Team Tenure & 0.00 & 0.01 & 0.01 & 0.01 & 0.01 \\
\hline Individual Age & 0.00 & 0.01 & 0.01 & 0.01 & 0.01 \\
\hline Instructor & 0.10 & 0.09 & 0.06 & 0.06 & 0.01 \\
\hline \multicolumn{6}{|c|}{ Main Effects (Level 1) } \\
\hline Gender & & 0.11 & 0.09 & -0.22 & 1.87 \\
\hline Race & & 0.40 & 0.39 & 1.01 & 3.46 \\
\hline \multicolumn{6}{|c|}{ Main Effect (Level 2) } \\
\hline Shared Leadership & & & -0.42 & -0.27 & 1.16 \\
\hline Gender Diversity & & & 0.63 & 0.53 & 0.36 \\
\hline Racial Diversity & & & 0.25 & 0.33 & 0.22 \\
\hline \multicolumn{6}{|c|}{ Two-way Cross-Level Interactions } \\
\hline \multicolumn{2}{|c|}{ Shared Leadership X Gender } & & & 0.44 & -2.40 \\
\hline \multicolumn{2}{|c|}{ Shared Leadership X Race } & & & -0.93 & -4.20 \\
\hline Gender X Race & & & & 0.02 & $-7.16^{*}$ \\
\hline \multicolumn{6}{|c|}{ Three-way Cross-Level Interactions } \\
\hline \multicolumn{3}{|c|}{ Shared Leadership X Gender X Race } & & & $10.50^{*}$ \\
\hline $\begin{array}{l}\text {-2 Restricted Log } \\
\text { Likelihood }\end{array}$ & 218 & 216 & 215 & 215 & 209 \\
\hline Deviance Difference & 3 & 2 & 1 & 0 & 6 \\
\hline $\mathrm{df}$ & & 2 & 3 & 3 & 1 \\
\hline $\mathrm{R}^{2}$ & 0 & $4.9 \%$ & $5.2 \%$ & $4.8 \%$ & $17 \%$ \\
\hline Change in $\mathrm{R}^{2}$ & & & $.3 \%$ & $-4 \%$ & $.12 \%$ \\
\hline \multicolumn{6}{|c|}{$*: \mathrm{p}<.05, * *: \mathrm{p}<0.01, * * *: \mathrm{p}<0.001$} \\
\hline
\end{tabular}

Table 4. Results of Multilevel Analysis 


\begin{tabular}{|c|c|c|}
\hline Hypothesis & Supported & $\begin{array}{c}\text { Level of Analysis } \\
\text { and } \\
\text { Sample Size }\end{array}$ \\
\hline 1 & Yes & Individual, N=78 \\
\hline 2 & Yes & Team, N=22 \\
\hline 3 & Yes & Team, N=22 \\
\hline 4 & No & Team, N=22 \\
\hline 5 & Yes & Team, $\mathrm{N}=\mathbf{2 2}$ \\
\hline
\end{tabular}

Table 6: Results

\begin{tabular}{|c|c|c|c|c|}
\hline \multirow[t]{2}{*}{$\begin{array}{c}\text { Independent } \\
\text { Variables } \\
\end{array}$} & \multicolumn{2}{|c|}{$\begin{array}{c}\text { Team } \\
\text { Satisfaction }\end{array}$} & \multicolumn{2}{|c|}{ Performance } \\
\hline & 1 & 2 & 1 & 2 \\
\hline \multicolumn{5}{|c|}{ Controls } \\
\hline Team Size & 0.01 & 0.23 & 0.48 & 0.42 \\
\hline Team Tenure & 0.00 & 0.00 & 0.02 & 0.01 \\
\hline Team Age & 0.01 & -0.01 & 0.38 & 0.45 \\
\hline Instructor & -0.40 & -0.06 & -9.03 & -10.11 \\
\hline Gender Div. & -1.08 & -1.33 & -13.5 & -13.6 \\
\hline Racial Div. & -1.1 & -1.23 & 9.14 & 9.36 \\
\hline \multicolumn{5}{|c|}{ Main Effect } \\
\hline $\begin{array}{c}\text { Shared } \\
\text { Leadership }\end{array}$ & & $5.0^{* *}$ & & $-28.7^{*}$ \\
\hline $\begin{array}{c}\text { Team } \\
\text { Identification }\end{array}$ & & 0.71 & & $6.21 *$ \\
\hline \multicolumn{5}{|c|}{$*: \mathrm{p}<.05, * *: \mathrm{p}<0.01, * * *: \mathrm{p}<0.001$} \\
\hline $\mathrm{R}^{2}$ & $13 \%$ & $64 \%$ & $40 \%$ & $62 \%$ \\
\hline Change $\mathrm{R}^{2}$ & & $50 \%$ & & $22 \%$ \\
\hline \multirow[t]{2}{*}{$\mathrm{F}$} & 0.33 & 2.4 & 1.2 & 3.05 \\
\hline & & 21 & & 21 \\
\hline
\end{tabular}

Table 5. Results of OLS Analysis

\section{DISCUSSION}

The objective of this study was to examine how shared leadership impacts team identification, satisfaction and actual performance of virtual teams. Prior literature has assumed that the impact of shared leadership would be positive $[5,13]$. However, results of this study indicate that shared leadership has both positive and negative effects on virtual teams at both the team and the individual level. At the individual level shared leadership promotes team identification and team satisfaction. However, at the individual level, shared leadership reduces team identification for non-white females and decreases team performance. Results of this study suggest that shared leadership can have both positive and negative effects (see Table 6).

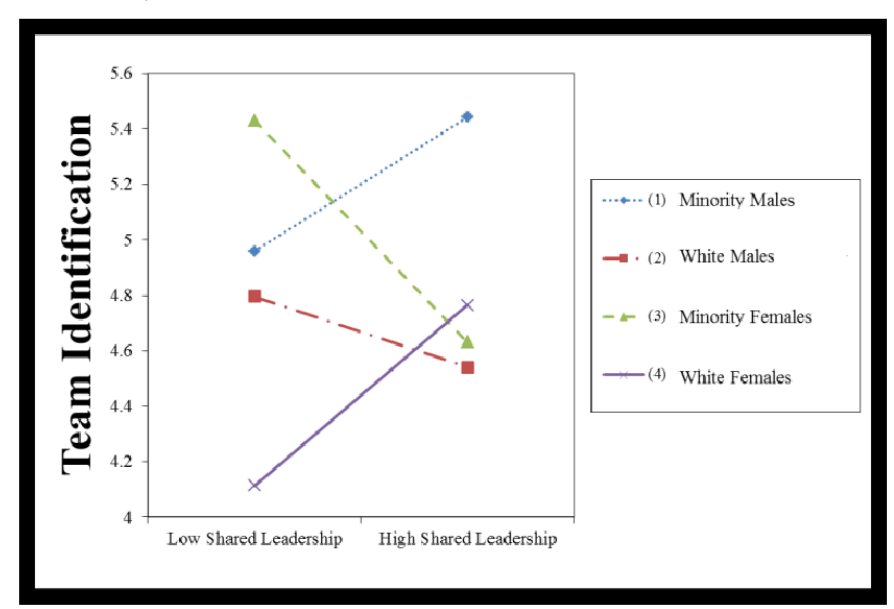

Figure 2: Multilevel Analysis of Shared Leadership

\section{Contributions}

This study makes three key contributions to the literature on virtual teams. First, this study sheds light on the impact of shared leadership in virtual teams. Although shared leadership has been shown to increase knowledge sharing, trust, constructive interactions, team cohesion and team creativity $[5,26]$ it has not been shown to increase objective virtual team performance $[5,13]$. This study contributes to this literature by confirming that shared leadership has positive impacts on another construct measuring the quality of team interactions, satisfaction. In other words, this is another study that found that shared leadership generally improves team interactions. This study also extends the literature on virtual teams by demonstrating that shared leadership can actually decrease team performance in virtual teams. Where prior studies hoped to find positive impacts and failed to find any $[5,13]$, this study predicted and found negative effects in an objective measure of team performance. Whereas team relationship variables are selfreported, including Lee et al. [26] the measure of team creativity, the measure of team performance was provided by someone from outside of the team. This means that despite the fact that virtual team members generally report better interactions with more shared leadership these better interactions may come at the expense of actual virtual team performance.

Two, this study contributes to the literature on team identification and virtual teams. Prior research has found that identification in virtual teams can help reduce the negative effects of member distribution on conflict in virtual teams [22, 34]; however, few studies have directly examined and found a link between team identification and virtual team performance. This study contributes to this 
literature by providing evidence that team identification can have similar positive effects on the performance of virtual teams as it does in face to face teams.

Three, this study contributes to the literature on team diversity in virtual teams. Fiol and O'Connor [17] proposed that team diversity could reduce the salience of the team as a target for identification in virtual teams. Although the negative effects of team diversity on identification in virtual teams have not been empirically verified this study takes a multi-level approach to the problem. Results indicate that individuals differ in their ability to identify with the team and that those differences are based, in part, on their individual race and gender. In the case of white women and non-white males, shared leadership increases the likelihood that they would identify with the team. However, the impact on non-white females was the opposite. Nonetheless, it is clear that shared leadership plays an important role in an individual's identification with their virtual team.

\section{Implications for Theory}

This study has several implications for theory. One, most researchers have all assumed that shared leadership would increase the performance of virtual teams $[13,5,26]$. As a result, prior research has been based on the idea that shared leadership should be encouraged. However, the results of this study provided evidence that we should not always expect positive effects from shared leadership and that researchers may need to theorize about when and why shared leadership is good or bad for the performance of virtual teams.

Two, the results of this study provide evidence that the impacts of race and gender can materialize at the individual level, independent of the virtual team. The effects of gender and race in this study cannot be attributed to the composition of the team nor the interactions within the teams. In fact, the correlation between gender and racial diversity with team identification are both non-significant. In addition, table 1 , indicates that women were the majority in 16 of the 22 virtual teams. This means that women were not necessarily the minority in most teams. Still, gender plays an important role in determining an individual's identification with their virtual team. Results indicate that the effects of race and gender on identification may not be the result of team interactions but individual experiences that existed before the team had any interactions.

Third, because the impact of shared leadership on nonwhite females had the opposite effect there is a need to rethink what mechanisms are at work. Work by ThomasHunt \& Phillips, [51] offers additional insights on the observed effects of non-white females. Thomas-Hunt \& Phillips [51] shows that female experts are less influential and less liked than male experts in mixed-gender groups because shared leadership and expertise recognition are related. It is possible that for non-white females increases in shared leadership may have been accompanied by feelings of resentment and dislike from other members. This may explain why higher levels of shared leadership lead to lower levels of identification. Nonetheless, the results demonstrate the importance of taking a multi-level approach to understanding the effects of race and gender in virtual teams.

This study has several limitations. First, like all crosssectional research it is difficult to draw causal inferences. However, by using an objective indicator of team performance this study reduces the impact of common method bias normally associated with cross sectional research. This also uses self-reported measures of race and gender. However, other conceptualization and measures of gender and race could provide different results. This study also uses students that are enrolled in distance education course. As such, there are limits to how general the results of the study are to other contexts.

\section{Design Implications}

Despite the negative effective of shared leadership on performance in virtual teams, shared leadership has been found to increase team performance in collocated teams [12]. The difference may be due to the inability of virtual teams to coordinate their work across space and time. It may be much easier to coordinate work when teams are collocated rather than dispersed. Future collaborative systems should be designed with the intent on helping virtual teams effectively coordinate their work. Awareness systems can be designed with features that allow any member to act as a leader at any moment. These awareness systems can provide real time data and an interface which allows any user to assume control over the team operations. In summary, future collaborative systems should be designed with the intent on supporting shared leadership through the team.

\section{Practical Implications}

The paper has several practical implications. Managers may want to balance the tradeoffs between the positive and negative effects associated with shared leadership. For example, teams are often assembled with the sole purpose of building consensus. In consensus building, virtual team managers may promote shared leadership as a way of increasing better team interactions. However, when performance is important managers may appoint a single leader. Because shared leadership does not imply a leaderless team this study has implications for team leaders of virtual teams. Team leaders may want to employ some type of shared leadership when virtual team relations are bad and then centralized leadership, later to encourage performance at other times. That may translate into allowing the team as a whole to have more authority to make decisions at certain times and less authority during other times.

\section{Conclusion}

This paper also sought to extend our understanding of the role of shared leadership on race, gender and team 
identification in virtual teams. This paper found that the impact of shared leadership on an individual's identification with the team was moderated by their race and gender. Shared leadership increased team satisfaction but decreased team performance while team identification increased team performance but had no impact on team satisfaction. By taking a multi-level approach we were allowed to see how the impact of shared leadership on team identification was moderated by both race and gender.

\section{REFERENCES}

1. Alles, M and Datar, S. Control Implications of Worker Identification with Firm Sales Success. Management Accounting Research, 13, 2, (2002), 173-190.

2. Alnuaimi, O. Maruping, L.M. Robert, L.P. Social Loafing in Brainstorming CMC Teams: The Role of Moral Disengagement. In Proc. HICSS 2009, IEEE Press (2009), 1-9.

3. Alnuaimi, O.A., Robert, L.P., and Maruping, L.M. Team size, dispersion, and social loafing in technologysupported teams: A perspective on the theory of moral disengagement. Journal of Management Information Systems 27, 1 (2010), 203-230.

4. Avolio, B. J., Kahai, S. R., and Dodge, G. E. ELeadership: Implications for Theory, Research, and Practices. The Leadership Quarterly. 11, 4 (2001), 61568.

5. Balthazard, P., Waldman, D., Howell, J. and Atwater, L. Shared Leadership and Group Interaction Styles in Problem-Solving Virtual Teams. In Proc. HICSS 2004, IEEE Press (2004), 110043-110053.

6. Bass, B. M., and Stogdill, R. M. Bass \& Stogdill's handbook of leadership: Theory, research, and managerial applications. (3rd Ed.). New York: The Free Press, 1990.

7. Blau, P.M. 1977. Inequality and Heterogeneity: A Primitive Theory of Social Structure. New York, NY: Free Press.

8. Bliese, P. D. 2000. Within-group agreement, nonindependence, and reliability: Implications for data aggregation and analysis. In K. J. Klein and S.W.J. Kozlowski (Eds.), Multilevel theory, research, and methods in organizations: Foundations, extensions, and new directions: 349-381, San Francisco: Jossey-Bass.

9. Bos, N.D., Buyuktur, A., Olson, J.S., Olson G.M. and Voida, A. Shared identity helps partially distributed teams, but distance still matters. In Proc. Group 2010, ACM Press (2010), 89-96.

10. Briggs, R. O., Vreede, G.J . de, and Reinig, B. A. A theory and measurement of meeting satisfaction. In Proc. HICSS 2003, IEEE Press (2003).

11. Brown, R. J., Condor, F., Mathews, A., Wade, G. and Williams, J. A. Explaining intergroup differentiation in an industrial organization. Journal of Occupat. Psyc. 59, 4, (1986), 273-287.

12.Carson, J. B., Tesluk, P. E., and Marrone, J. A. Shared leadership in teams: An investigation of antecedent conditions and performance. Academy of Management Journal 50, 5 (2007), 1217-1234.

13. Carte, T. A., Chidambaram, L., and Becker, A. Emergent leadership in self-managed virtual teams: A longitudinal study of concentrated and shared leadership behaviors. Group Decision and Negotiation 15, 4, (2006), 323-343.

14. Cohen, J. Statistical Power Analysis for the Behavioral Sciences (second Ed.). Lawrence Erlbaum Associates (1988).

15. Cramton, C.D. The mutual knowledge problem and its consequences for dispersed collaboration. Organization Science. 12, 3 (2001), 346-371.

16.Dennis, A.R., Robert, L.P., Curtis, A.M., Kowalczyk, S.T., and Hasty, B.K. Trust is in the Eye of the Beholder: A Vignette Study of Postevent Behavioral Controls' Effects on Individual Trust in Virtual Teams. Information Systems Research. 23, 2, (2012), 546-558.

17.Fiol, C. M., and O'Connor, E. J. 2005. Identification in face-to-face, hybrid, and pure virtual teams: Untangling the contradictions. Organization Science, 16, 1 (2005), 19-32.

18. Fornell, C. and Larcker, D.F. Evaluating structural equations models with unobservable variables and measurement error. Journal of Marketing Research. 18, 1, (1981), 39-50.

19. Gibson, C. B., and Gibbs, J. L. Unpacking the concept of virtuality: The effects of geographic dispersion, electronic dependence, dynamic structure, and national diversity on team innovation. Administrative Science Quarterly. 51, 3, (2006), 451-495.

20. Gronn, P. Distributed leadership as a unit of analysis. Leadership Quarterly. 13, 4, (2002), 423-451.

21. Hambley, L. A., O’Neill, T. A., and Kline, T. J. B. Virtual team leadership: The effects of leadership style and communication medium on team interaction styles and outcomes. Organizational Behavior \& Human Decision Processes. 103, 1, (2007), 1-20.

22. Hinds, P. J. and Mortensen, M. Understanding conflict in geographically distributed teams: The moderating effects of shared identity, shared context, and spontaneous communication. Organization Science, 16, 3 (2005), 290-307.

23.Hogg, M. A and Abrams, D. (1988). Social identifications: A social psychology of intergroup relations and group processes. London: Routledge. 
24. Jarvenpaa, S. L., K. Knoll, D. E. Leidner. Is anybody out there? Antecedents of trust in global virtual teams. J. Management Inform. Systems. 14, 4, (1998), 29-64.

25. Kocolowski, M. D. Shared Leadership: Is it Time for a Change? Emerging Leadership Journeys, 3, 1, (2010), 22-32.

26. Lee, K., Lee, D., and Seo, Y. Effects of Shared Leadership on Team Creativity through Knowledgesharing in an e-Learning Environment. In Proc. ICUIMC 2011, ACM Press (2011).

27. Luther, K. and Bruckman, A. Leadership in Online Creative Collaboration. In Proc. CSCW 2008, ACM Press (2008), 343-352.

28. Major, T. Time is running out for leadership by committee: Modern business practice is challenging German law, reports tony major: Financial Times, (2001), 29-29.

29. Marks, A. and Lockyer, C. 2005. Debugging the System: The impact of location on the identity of software team members. Intern. Journal of Human Resource Management. 16, 2 (2005), 219-237.

30. Martins, L. L, Gilson, L. L. and Maynard, M. T. Virtual teams: What do we know and where do we go from here? Jour. of Manag., 30, 6, (2004), 805-835.

31. Mayo, M. C., Meindl, J. R., and Pastor, J. C. 2003. Shared leadership in work teams: A social network approach. In C. Pierce, \& J. Conger (Eds.), Shared leadership: Reframing the hows and whys of leadership: 193-214. Thous. Oaks, CA: Sage.

32. Misiolek, N., and Heckman, R. Patterns of emergent leadership in virtual teams. In Proc. 38th HICSS 2005, IEEE Press (2005).

33. Mor Barak, M. E., Cherin, D. A., and Berkman, S. Organizational and personal dimensions in diversity climate: Ethnic and gender differences in employee diversity perceptions. Journal of Applied Behavioral Sciences, 34, 1 (1998), 82-104.

34. Mortensen, M., P. J. Hinds. Conflict and shared identity in geographically distributed teams. Internat. J. Conflict Management. 12, 3, (2001), 212-238.

35. Muethel, M. and Hoegl, M. Cultural and societal influences on shared leadership in globally dispersed teams. Journal of International Management. 16, 3 (2010), 234-246.

36. Newell, J., Maruping, L.M., Riemenschneider, C. and Robert, L.P. Leveraging E-Identities: The Impact of Perceived Diversity on Team Social Integration and Performance. In Proc. ICIS 2008. http://aisel.aisnet.org/icis2008/46

37. Newell, J. Robert, L.P., Riemenschneider, C. Maruping, L.M. Influencing Individual Perceptions of Deep Level
Diversity in Virtual Learning Teams (VLT), In Proc. HICSS 2009, IEEE Press (2009).

38. O'Leary, M., and Cummings, J. N. The spatial, temporal, and configurational characteristics of geographic dispersion in work teams. MIS Quarterly. 31(3), (2007), 433-452

39. Olson, G. M., and Olson, J. S. Distance Matters. Human Comp. Inter. 15, (2000), 139-179.

40. Pearce, C. L., and Conger, J. A. 2003. All Those Years Ago: The Historical Underpinnings of Shared Leadership. In C. L. Pearce \& J. A. Conger (Eds.), Shared Leadership: Reframing the Hows and Whys of Leadership: 1-18. Thousand Oaks, CA: Sage Publications.

41.Pearce, C.L., Manz, C.C. and Sims, H. P. Is Shared Leadership the Key to Team Success?. Organizational Dynamics, 38, 3 (2009), 234-238.

42. Plotnick, L., Hiltz, S. R., Ocker, R.J., and Rosson, M.R. Leadership Roles and Communication Issues in Partially Distributed Emergency Response Software Development Teams: A Pilot Study, In Proc. HICSS 2008, IEEE Press (2008).

43. Polzer, J.T., B. Crisp, S.L. Jarvenpaa, J.W. Kim. Extending the Faultline Concept to Geographically Dispersed Teams: How Colocated Subgroups Can Impair Group Functioning. Academy of Management Journal. 49, 4, (2006), 679-692.

44. Powell, A., Piccoli, G., Ives, B. Virtual teams: A review of current literature and directions for future research. The DATA BASE for Advances in Information Systems, 35, 1 (2004), 6-36.

45. Robert, L.P., Dennis, A.R., and Ahuja, M.K. 2008. Social Capital and Knowledge Integration in Digitally Enabled Teams. Information Systems Research 19, 3 (2008), 1-21.

46. Robert, L. P., Dennis, A. R., and Hung, Y.-T. C. Individual Swift Trust and Knowledge-Based Trust in Face-to-Face and Virtual Team Members. Jour. of Manage. Info.Sys. 26, 2 (2009), 241-279.

47. Scott, C. R. Identification with multiple targets in a geographically dispersed organization. Management Communication Quarterly. 10, 4, (1997), 491-522.

48. Shapiro, D., Furst, S., Spreitzer, G. and Von Glinow, M. Transnational teams in the electronic age: are team identity and high performance at risk? Journal of Organizational Behaviour. 23, 4, (2002), 445-467.

49. Srinivasan, S.S., Maruping, L.M., Robert, L.P. Idea Generation in Technology-Supported Teams: A Multilevel Motivational Perspective System Science In Proc. HICSS 2012, IEEE Press (2012), 247-256.

50. Tajfel, H. and Turner, J. C. 1986. The Social Identity Theory of Inter-Group Behavior. In S. Worchel 
and L. W. Austin (Eds.), Psychology of Intergroup Relations: 7-24. Chicago, IL: Nelson.

51. Thomas-Hunt, M.C. and Phillips, K. W. When what you know is not enough: The effects of gender on expert's influence within work groups. Personality and Social Psychology Bulletin. 30, 12, (2004), 1585-1598.

52. Van Dick, R., van Knippenberg, D., Hägele, S., Guillaume, Y. R. F., and Brodbeck, F. C. Group diversity and group identification: The moderating role of diversity beliefs. Human Relations. 61, 10, (2008), 1463-1492.

53. Voida, A., Bos, N., Olson, J., Olson, G. and Dunning, L. 2012. Cross-cutting faultlines of location and shared identity in the intergroup cooperation of partially distributed groups. In Proc. CHI 2012, ACM Press (2012), 3101-3110.

54. Wakefield, R., Leidner, D., \& Garrison, G. A Model of Conflict, Leadership and Performance in Virtual Teams. Information Systems Research, 19, 4, and (2008), 434-455.
55. Williams, K.Y., and O'Reilly, C.A. 1998. Demography and Diversity in Organizations: A Review of 40 Years of Research. In Shaw and L.L. Cummings (Eds.), Research in Organizational Behavior 20: 77-140, Greenwich, CT: B.M. JAI.

56. Yamaguchi, R., Bos, N., and Olson, J.S., 2002. Emergent leadership in small groups using computermediated communications. In Proc. of CSCL'02, ACM Press (2002), 138-143.

57. Yoo, Y. and Alavi, M. Emergent Leadership in Virtual Teams: What do Emergent Leader. Do? Information and Organization, 14, 1, (2004), 27-58.

58.Zhu, H., Kraut, R.E. and Kittur, A. Effectiveness of shared leadership in online communities. In Proc. CSCW 2012, ACM Press (2012), 407-416.

59.Zigurs, I. Leadership in Virtual Teams: Oxymoron or Opportunity? Organizational Dynamics. 31, 4, (2003), 339-351. 